\title{
Fe-Al binary oxide nanosorbent: Synthesis, characterization and phosphate sorption property
}

\author{
A.S. Tofik ${ }^{\mathrm{a}}$, Abi M. Taddesse ${ }^{\mathrm{a}, *}$, K.T. Tesfahun ${ }^{\mathrm{a}}$, G.G. Girma ${ }^{\mathrm{b}}$ \\ a Department of Chemistry, Haramaya University, Haramaya, Ethiopia \\ b Physics Department, Dire Dawa University, Dire Dawa, Ethiopia
}

\section{A R T I C L E I N F O}

\section{Article history:}

Received 17 December 2015

Received in revised form 15 April 2016

Accepted 17 April 2016

Available online 21 April 2016

\section{Keywords:}

Eutrophication

Nanosorbent

Fe-Al binary oxide

Adsorption

Phosphorus

\begin{abstract}
A B S T R A C T
Phosphorous removal using efficient treatment approach such as adsorption is vital for the control of eutrophication. In this study, nanosized Fe-Al binary oxide sorbent was synthesized through a modified gel evaporation method and employed for adsorption of phosphate from aqueous system. The nanosorbent was characterized by x-ray diffraction (XRD), scanning electron microscope coupled with energy dispersive $\mathrm{X}$-ray spectroscopy (SEM/EDX), tunneling electron microscopy (TEM), Fourier transform infrared spectroscopy (FTIR) and flame atomic absorption spectroscopy (FAAS). Langmuir model showed the best fit to the experimental data with a maximum adsorption efficiency of $16.4 \mathrm{mg} / \mathrm{g}$. Having all parameters optimized, it has been found that the nanosorbent exhibited $99.86 \%$ phosphate adsorption efficiency. The effect of co-existing anions on the adsorption of phosphate was also studied and no significant effect on the efficiency of the nanosorbent was observed due to competing ions such as fluoride. Desorbabilty of phosphate was investigated and found to be increased with increasing $\mathrm{pH}$. The results of thermodynamic studies indicated that the process is spontaneous and endothermic. Both macroscopic and microscopic approaches were employed to predict the mechanism of phosphate adsorption on the Fe-Al binary oxide nanosorbent. Accordingly, the phosphate adsorption is presumed to occur via the replacement of surface hydroxyl groups by the phosphate species and formation of innersphere surface complexes at the water/oxide interface.
\end{abstract}

(c) 2016 Elsevier Ltd. All rights reserved.

\section{Introduction}

Phosphorus has been regarded as a limiting nutrient responsible for eutrophication of water bodies. The presence of trace amount of phosphate (even less than $1 \mathrm{ppm}$ ) in treated wastewater is often responsible for eutrophication; particularly in lakes and slow moving rivers [1]. Therefore, removing phosphate is very important before discharging wastewater into the water environment.

Several techniques have been developed for P removal which includes chemical precipitation [2], biological removal [3], reverse osmosis [1], electrodialysis [4], ion exchange [5], constructed wetlands [6] and adsorption [7,8]. Among these available approaches, chemical precipitation and biological removal in general are not able to meet the stringent effluent standards while ion exchange, electrodialysis and reverse osmosis require high investment and operation costs. Compared with these techniques,

\footnotetext{
* Corresponding author at: P.O.Box 90, Haramaya University Haramaya, Ethiopia. E-mail address: abi92003@yahoo.com (A.M. Taddesse).
}

adsorption methods proved to be more promising due to their low cost, effective treatment in dilute solutions, and high uptake capacity. Another attractive feature of this technique is that the nutrient-loaded filters can be used in agriculture as phosphate fertilizers [9]. This particular feature is important since phosphate is recognized as one of the natural resources that could possibly be exhausted in the near future [10].

A large number of materials from natural minerals to synthetic ones have been used as adsorbents to adsorb phosphate from wastewater. These adsorbents include minerals [11], soils [12], industrial by-products [13-16,54], and synthetic products [17-19]. Considerable number of reports has shown that excellent and efficient phosphorus adsorbents are all characterized by their high iron, alumina, calcium and manganese contents [20-25]. Thus, substrates with high contents of these materials can be efficient phosphate sinks in immobilizing phosphate from soils and water bodies.

Mixed metal oxides exhibit surface properties that mimic the natural systems more closely than their individual components. Multi-component sorbents demonstrate physico-chemical properties significantly different from those of their single counter 
parts. It is these differences in physico-chemical properties that are considered to be the major reasons for differences in sorption behavior between multi- and single-component systems [20]. For example, increased fixation of $\mathrm{Cu}$ and $\mathrm{Pb}$ in $\mathrm{Fe} / \mathrm{Al}$ oxide system (compared to single counter parts) is attributed to increased surface area and surface charge [26,27]. Although sorption characteristics of single component $\mathrm{Al}$ or Fe hydr (oxides) have been widely studied, limited work has been conducted on the sorption characteristics of mixed Al-Fe binary oxide especially at nanoscale.

Adsorbents synthesized with iron oxide that incorporate different metal ions for high adsorption performance have been studied. Al (III), Cr (III), Cu (II), Mn (IV), Ti (IV) and Zr (IV) [28-33,51] ions had been introduced into iron oxide to form bimetallic/ trimetalic oxide adsorbents for phosphate sorption. Among these mixed oxides $\mathrm{Fe}-\mathrm{Cu}, \mathrm{Fe}-\mathrm{Zr}$ and Ti-Fe binary oxides have been prepared in crystalline form where as the remaining are amorphous. Reports documented in relation to phosphate sorption using Fe-Al binary oxides are all in amorphous forms though crystalline forms of the oxyhydroxides are reported for photocatalytic applications [34,35]. Hence, there is still a dearth of information related to the synthesis, characterization and sorption property studies of Fe-Al binary mixed oxide in nanocrystalline form for phosphate removal from wastewater. Recently, materials with nanostructure have gained special attention in the field of solute adsorption from the liquid phase due to small particle size, large surface area to volume ratio, high in situ reactivity and absence of diffusion resistance [36,37].

In the present work, we report the synthesis and phosphate sorption behavior of nanocrystaline Fe-Al binary oxide sorbent. The synthesis involved a series of Fe-Al binary oxides with different $\mathrm{Fe} / \mathrm{Al}$ ratios (from 0 to 30\%) and the binary system with the smallest size was selected and tested for phosphate adsorption study. The adsorption kinetics, adsorption isotherms and desorption studies have been carried out. Additionally, the influence of operating parameters such as solution $\mathrm{pH}$, ionic strength and coexisting anions on phosphate adsorption were investigated. Phosphate adsorption mechanism was also elucidated in the present paper based on macroscopic and microscopic approaches. The as-synthesized Fe-Al nanosorbent exhibited potentially high (99.86\%) phosphate adsorption efficiency. The effect of co-existing anions on the adsorption of phosphate showed no significant effect making the material a promising sorbent for phosphate sorption from aqueous systems in the presence of interfering ions.

\section{Methodology}

\subsection{Synthesis of the nanosorbent}

Gel evaporation method [38] with some modifications was followed to synthesize Fe-Al binary oxide nanosorbent. The percentage of aluminum in the binary systems varied from 0 to $30 \%$. The starting materials [ferric nitrate nonahydrate $\mathrm{Fe}$ $\left(\mathrm{NO}_{3}\right)_{3} \cdot 9 \mathrm{H}_{2} \mathrm{O}$ and aluminum nitrate nonahydrate $\left.\mathrm{Al}\left(\mathrm{NO}_{3}\right)_{3} \cdot 9 \mathrm{H}_{2} \mathrm{O}\right]$ were dissolved in ethylene glycol at a molar ratio of (total metal nitrates: ethylene glycol=1:3) with the addition of a minimum volume of water enough to dissolve the nitrates. The resulting solution was warmed on hot plate stirrer at $90^{\circ} \mathrm{C}$ to evaporate the solvents, after which the nitrate glycol mixture auto-ignited, producing voluminous foam and finally yielding a loose powder. The powders were dry ground and calcined at three different temperatures: $300^{\circ} \mathrm{C}, 600^{\circ} \mathrm{C}$ and $900^{\circ} \mathrm{C}$ for $5 \mathrm{~h}$. The as synthesized powders were designated according to the $\mathrm{Al}$ content and temperature of calcinations. For example, the mixed oxide containing $0 \% \mathrm{Al}$ calcined at $300^{\circ} \mathrm{C}$ was designated as $0 \mathrm{Al} 300$, and so on. A total of nine samples were synthesized and based on the XRD results, the sample with the smallest crystalline size was selected for the subsequent sorption experiment.

\subsection{Elemental analysis}

The percentage of iron as iron oxide in all the as-synthesized powders was determined by flame atomic absorption spectrophotometer (AAS). $0.5 \mathrm{~g}$ of the as-synthesized powders was digested with concentrated nitric acid $(7 \mathrm{~mL})$, concentrated hydrochloric acid $(4 \mathrm{~mL})$ and hydrogen peroxide $(2 \mathrm{~mL})$ using acid digestion tube till clear solution appeared. The samples were transferred to $100 \mathrm{~mL}$ volumetric flasks and brought to volume using deionized water. $1 \mathrm{~mL}$ of this solution was diluted further to $50 \mathrm{~mL}$ and the concentration of iron was read from the solution in $50 \mathrm{~mL}$ volumetric flasks using AAS [20].

\subsection{Characterization of the as-Synthesized powder}

X-ray diffraction (XRD) analysis of the synthesized particles was made using an $\mathrm{X}$-ray powder diffractometer (Philips Analytical $\mathrm{PW}-1710)$ equipped with $\mathrm{Cu} \mathrm{K} \alpha$ radiation $(\lambda=0.1541 \mathrm{~nm})$ at a scan speed of $2^{\circ} / \mathrm{min}$ from $10^{\circ}$ to $80^{\circ}$, operated at voltage $40 \mathrm{kv}$ and applied potential current $30 \mathrm{~mA}$. The average crystallite size was determined from the XRD peaks using Debye-Scherrer equation and the sample with the smallest size was selected for the subsequent sorption studies. The surface morphology of the prepared adsorbent was observed by scanning electron microscopy (SEM) using JSM-6700F LV microscope. The elemental composition of the sample was further analyzed by energy dispersive analysis system using EDX GENESIS (EDAX, Ltd., USA). Transmission electron micrographic (TEM) images were recorded on a H800 transmission electron micrograph (Hitachi, Japan). The IR spectra of the prepared adsorbent before and after phosphate adsorption were measured by a Fourier transform infrared spectrometer (SHIMADZU 1730, Japan).

\subsection{Batch adsorption studies}

Batch mode adsorption studies for phosphate were carried out in $50 \mathrm{~mL}$ Erlenmeyer flask. The batch adsorption process was optimized with respect to $\mathrm{pH}$, adsorbent dose, speed of agitation, contact time and initial phosphate ion concentration. For each run, the resulting suspension of the phosphate ions was filtered using a Whatman No.1 filter paper and the filtrate was analyzed calorimetrically for the corresponding phosphate ion concentration. Removal efficiency was finally calculated by using the relationship given below.

Adsorption $\%=\frac{C_{o}-C_{f}}{C_{0}} \times 100$

where $C_{o}=$ the initial concentrations $(\mathrm{mg} / \mathrm{L})$ and $C_{\mathrm{f}}=$ final concentrations $(\mathrm{mg} / \mathrm{L})$ of the phosphate ion.

The adsorption capacity of the phosphate ion is the concentration of the phosphate ion on the adsorbent mass and was calculated based on the mass balance principle,

$\mathrm{q}_{\mathrm{e}}=\frac{\mathrm{C}_{\mathrm{o}}-\mathrm{C}_{\mathrm{f}}}{\mathrm{m}} \mathrm{xV}$

where: $\mathrm{q}_{\mathrm{e}}=$ adsorption capacity of adsorbent $(\mathrm{mg} / \mathrm{g}), \mathrm{V}=$ the volume of reaction mixture $(\mathrm{L}), \mathrm{m}=$ the mass of adsorbent used $(\mathrm{g}), \mathrm{C}_{\mathrm{o}}=$ the initial concentrations $(\mathrm{mg} / \mathrm{L})$ and $\mathrm{C}_{\mathrm{f}}=$ final concentrations $(\mathrm{mg} / \mathrm{L})$ of the phosphate ion.

\subsubsection{Effect of $\mathrm{pH}$ and ionic strength}

To gain insight into the adsorption process, the influence of $\mathrm{pH}$ was studied as follows. Solutions containing $30 \mathrm{mg} / \mathrm{L}$ of phosphate 
were adjusted with $\mathrm{HCl}$ and $\mathrm{NaOH}$ solutions to the desired $\mathrm{pH}$ values from 2 to 9 . The other parameters such as adsorbent dose, agitation speed and contact time were kept constant. Effect of ionic strength was studied taking the initial phosphate concentration of $5 \mathrm{mg} / \mathrm{L}$. The solution $\mathrm{pH}$ was adjusted from 2 to 10 , the concentrations of $\mathrm{NaNO}_{3}$ were $0.1,0.01,0.001 \mathrm{M}$, respectively, and the contact time was $8 \mathrm{~h}$.

\subsubsection{Effect of adsorbent dosage}

The effect of adsorbent dosage was studied by using $0.05,0.075$, $0.1,0.5,1$ and $2 \mathrm{~g}$ of the adsorbent in $50 \mathrm{~mL}$ Erlenmeyer flask with phosphate ion concentration of $30 \mathrm{mg} / \mathrm{L}$ and the adsorption efficiency for each dose was determined by keeping other parameters $(\mathrm{pH}$, agitation speed, contact time and initial phosphate concentration) constant.

\subsubsection{Effect of agitation speed}

In this study, the effect of varying the agitation speed was investigated by keeping the other operating parameters $(\mathrm{pH}$, adsorbent dose, contact time and initial phosphate concentration) constant. A series of experiments was undertaken with different agitation speeds: 50, 100,120 140, 160 and $200 \mathrm{rpm}$.

\subsubsection{Effect of contact time}

The effect of contact time on phosphate sorption was determined by varying the contact time to $3,6,12,16,24$ and $48 \mathrm{~h}$ with the other parameters $(\mathrm{pH}$, adsorbent dose, agitation speed and initial phosphate concentration) kept constant.

\subsubsection{Effect of phosphate ion concentration}

The effect of phosphate concentration was determined considering the following initial phosphate ion concentration: $10,20,30,50,100,150$ and $200 \mathrm{mg} / \mathrm{L}$ keeping other parameters ( $\mathrm{pH}$, adsorbent dose, and agitation speed and contact time) constant.

\subsubsection{Adsorption isotherms}

Adsorption isotherms are mathematical models that describe the distribution of the adsorbate species among the liquid and solid phases based on a set of assumptions that are related to the heterogeneity or homogeneity of the solid surface, the type of coverage, and the possibility of interaction between the adsorbate species. In order to construct adsorption isotherms for the adsorbent, experiments were carried out by varying the initial phosphate ions concentration from 10 to $200 \mathrm{ppm}$ and with the adsorbent dose of $0.1 \mathrm{~g}$.

\subsubsection{Selectivity of phosphate adsorption}

The dependency of phosphate adsorption onto the as-synthesized powder in the presence of other anions which are commonly present in water namely $\mathrm{F}^{-}, \mathrm{SO}_{4}{ }^{2-}, \mathrm{HCO}_{3}{ }^{-}$and $\mathrm{NO}_{3}{ }^{-}$was investigated. $20 \mathrm{mg} / \mathrm{L}$ of these anions were prepared from $\mathrm{NaF}$, $\mathrm{Na}_{2} \mathrm{SO}_{4}, \mathrm{NaHCO}_{3}$ and $\mathrm{NaNO}_{3}$. The effect of mixture of anions and also the effect of individual anions were studied to estimate the selective adsorption of phosphate.

\subsubsection{Thermodynamic study}

Thermodynamic parameters shed valuable insight into feasibility and spontaneity nature of the adsorption process [54]. By plotting the graph $\operatorname{lnK}_{\mathrm{c}}$ versus $\mathrm{T}^{-1}$, the values of $\Delta \mathrm{H}$ and $\Delta \mathrm{S}$ were estimated from the slopes and intercepts and on the basis of this, the spontaneity of the process was assessed. Based on the above approach, the free energy change $(\Delta G)$, enthalpy change $(\Delta H)$ and entropy change $(\Delta S)$ were calculated for the sorbent.

\subsubsection{Kinetic studies}

Adsorption is time dependent process and it is very important to know the rate of the process and evaluate the adsorbent in removing phosphate from aqueous system. Kinetic models based on the capacity of the adsorbent have been investigated, such as the Lagergren's first-order equation and Ho's second-order expression [39,40]. The first-order equation of Lagergren and the pseudo second-order equation are the most widely used kinetic models to describe the sorption process. First-order rate expression of Lagergren considers that the rate of occupation of adsorption sites is proportional to the number of unoccupied sites. The Lagergren model proposed in 1898 assumes a first order adsorption kinetics and can be represented by the equation:

$\frac{\mathrm{dq}_{\mathrm{t}}}{\mathrm{dt}}=\mathrm{k}_{1}\left(\mathrm{q}_{\mathrm{e}}-\mathrm{q}_{\mathrm{t}}\right)$

where, $\mathrm{k}_{1}$ is the rate constant for pseudo-first order adsorption, $\mathrm{q}_{\mathrm{e}}$ and $\mathrm{q}_{\mathrm{t}}$ are the amount of phosphate adsorbed $(\mathrm{mg} / \mathrm{g})$ at equilibrium and at any time $t$, respectively. This equation can be integrated to yield a linearzed form at initial condition $\mathrm{q}_{\mathrm{t}}=0$, $\mathrm{t}=0$ and $\mathrm{q}_{\mathrm{t}}=\mathrm{t}$ and $\mathrm{t}=\mathrm{t}$.

$\log \left(q_{e}-q_{t}\right)=\log q_{e}-\frac{K_{1}}{2.303} t$

In this equation, the rate of adsorption is assumed to be proportional to the difference between the adsorption capacity at equilibruim $\left(\mathrm{q}_{\mathrm{e}}\right)$ and the adsorption capacity at time $\mathrm{t}\left(\mathrm{q}_{\mathrm{t}}\right)$. The pseudo- first order kinetics is applicable if the plot of $\log \left(\mathrm{q}_{\mathrm{e}}-\mathrm{q}_{\mathrm{t}}\right)$ against $t$ shows linear relationship. A straight line plot of log $\left(\mathrm{q}_{\mathrm{e}}-\mathrm{q}_{\mathrm{t}}\right)$ versus $\mathrm{t}$ was used to determine the first order rate constant, $\mathrm{k}_{1}$ and the adsorption capacity, $\mathrm{q}_{\mathrm{e}}$.

The pseudo second order rate equation is expressed as:

$\frac{\mathrm{dq}_{\mathrm{t}}}{\mathrm{dt}}=\mathrm{k}_{2}\left(\mathrm{q}_{\mathrm{e}}-\mathrm{q}_{\mathrm{t}}\right)^{2}$

where, $k_{2}$ is equilibrium rate constant of second order kinetics model $\left(\mathrm{g} \mathrm{mg}^{-1} \mathrm{~h}^{-1}\right)$. For boundary condition $\mathrm{t}=0$ to $\mathrm{t}=\mathrm{t}$ and $\mathrm{q}_{\mathrm{t}}=0$ to $\mathrm{q}_{\mathrm{t}}=\mathrm{q}_{\mathrm{e}}$, the integrated form of the equation becomes

$\frac{1}{q_{e}-q_{t}}=\frac{1}{q_{e}}+k_{2} t$

Then, the linearized form is:

$\frac{\mathrm{t}}{\mathrm{q}_{\mathrm{t}}}=\frac{1}{\mathrm{~K}_{2} \mathrm{q}_{\mathrm{e}}^{2}}+\frac{\mathrm{t}}{\mathrm{q}_{\mathrm{e}}}$

The pseudo-second order rate constant $\left(k_{2}\right)$ and the equilibrium adsorption capacity $\left(\mathrm{q}_{\mathrm{e}}\right)$ can be determined experimentally from the slope and intercept of the plot $t / q_{t}$ versus $t$. The plot $t / q_{t}$ versus $t$ should give a straight line if pseudo-second order kinetics is applicable. The kinetics of adsorption study was carried at initial phosphate concentration of $20 \mathrm{mg} / \mathrm{L}$ with corresponding adsorbent dose of $0.1 \mathrm{~g}$. The residual concentrations were measured at different time intervals.

\subsubsection{Desorption of phosphate}

Phosphate desorption was studied using phosphate loaded powder sample [41]. The powder was immersed in the regenerating solution and placed in shaker at $25^{\circ} \mathrm{C}$ for $12 \mathrm{~h}$. To this, $0.1 \mathrm{M}$ $\mathrm{NaOH}$ solution was used to effect the desorption. The desorbed adsorbate in the solution was finally recovered by filtration and analyzed for the corresponding phosphate ion concentration. The recovery percentage was obtained from the following relation.

Desorption Efficiency\% $=\frac{\text { Desorbed }}{\text { Adsorbed }} \times 100$ 

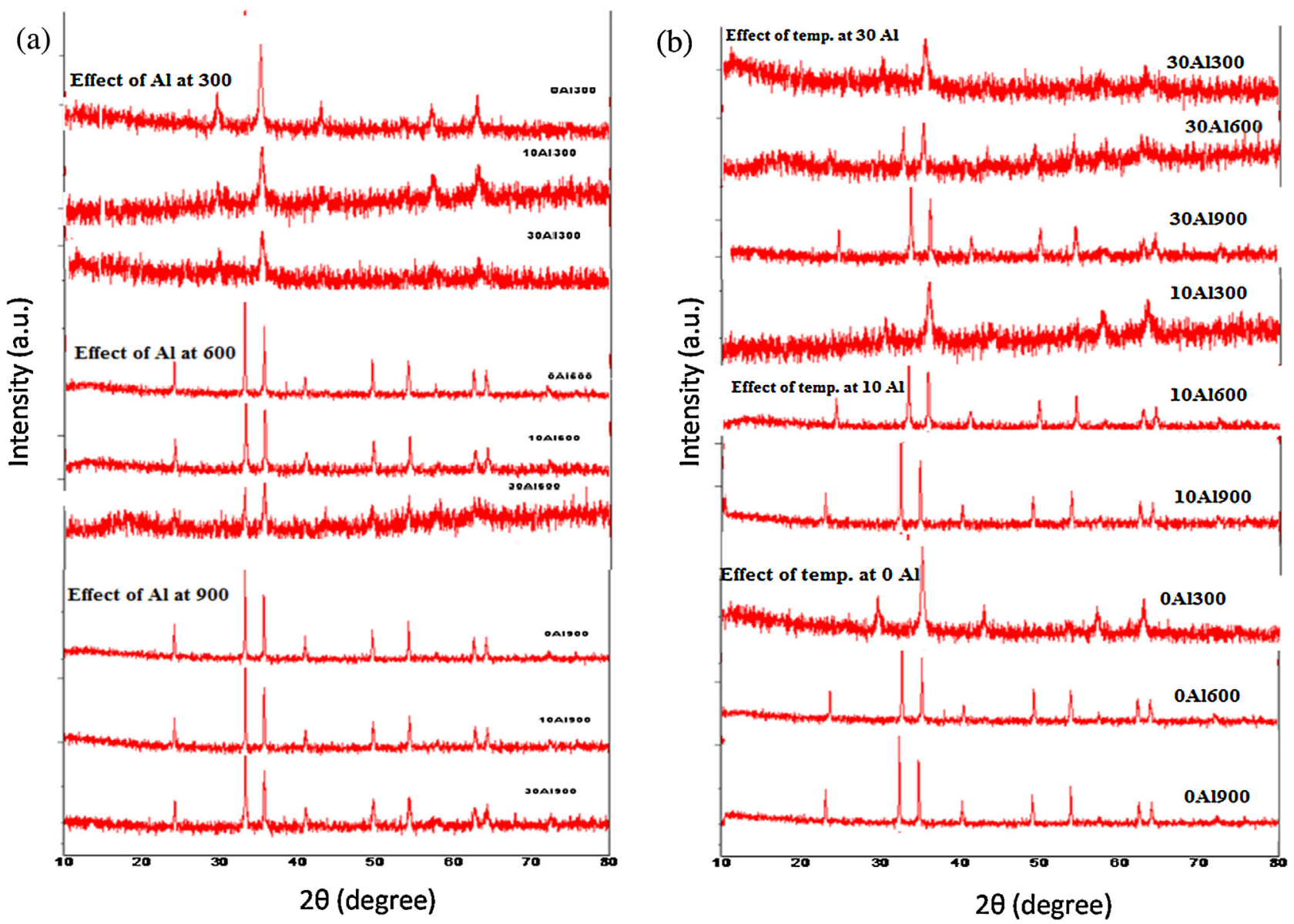

Fig. 1. Effect of Al content (a) and temperature (b) on the XRD patterns of the as-synthesized powders.

where, Desorbed = the concentration and/or the mass of the phosphate ion after the desorption process, Adsorbed $=(\mathrm{Co}-\mathrm{Ce})$ for each recovery process.

\subsubsection{Analysis of phosphate}

The analysis of phosphate was done spectrophotometrically using molybdenum blue method [42]. This involves reaction of phosphate ions with an acid solution containing molybdate and antimony ions to form an antimony phosphomolybdate complex followed by reduction of this complex with ascorbic acid to form a strongly colored molybdenum blue complex. The intensity of the blue color correlates to the concentration of phosphate. Concentrated solutions were diluted prior to determination and corrected with dilution factor.

\section{Results and discussion}

\section{1. $X R D$}

After calcinations at $300^{\circ} \mathrm{C}, 600^{\circ} \mathrm{C}$ and $900^{\circ} \mathrm{C}$, the crystalline phases in the samples were determined from the XRD patterns using the relevant ICDD data to investigate the structural changes caused by thermal treatment and alumina incorporation. At $300^{\circ} \mathrm{C}$, the peaks observed at $2 \theta$ values of $31,36,43,56.5$, and 63 for the sample $0 A 1300$ could be attributed to maghemite (Fig. 1a).

For the same sintering temperature, the peaks started to diminish with increasing alumina content from 10\% to 30\% indicating that increasing the alumina content decreases crystallinity (Fig. 1a). At $600^{\circ} \mathrm{C}$, more peaks are observed that were not distinct at $300^{\circ} \mathrm{C}$ for all iron alumina combination carried out under this study. The peaks at $2 \theta$ values of $24,33,36,41,49.5$, 55.6 and 64 correspond to hematite and the remaining peaks correspond to maghemite (Fig. 1a). At this temperature as well, the degree of crystallinity of iron oxide decreased with increasing alumina. At $900^{\circ} \mathrm{C}$, the peaks at $2 \theta$ values corresponding to 24,33 , $36,41,49.5,54.5,63,64.5,72.5$ are all associated with hematite (Fig. 1a). Increasing calcination temperature therefore increases crystal transformation of iron oxides from maghemaite to hematite significantly. The presence of alumina delays not only crystallization but also transformation from maghemite to hematite (Fig. 1b). The observed effect of thermal treatment and alumina incorporation to iron oxide in our study is similar to previous reports [3436]. No any peak presented was attributable to alumina in our result implying that alumina should be amorphous structure. In fact, crystallized alumina such as $\gamma-\mathrm{Al}_{2} \mathrm{O}_{3}$ might present under thermal treatment at $800^{\circ} \mathrm{C}$, but the amount may not be good enough to bring about this change at the concentration used in this

Table 1

Crystal size and percentage of $\mathrm{Fe}_{2} \mathrm{O}_{3}$ for the as-synthesized nanosorbent.

\begin{tabular}{lllll}
\hline Adsorbent & $2 \theta$ (degree) & $\beta$ (degree) & $\mathrm{D}(\mathrm{nm})$ & Percentage of $\mathrm{Fe}_{2} \mathrm{O}_{3}$ \\
\hline 0Al300 & 35.516 & 0.355 & 23.5 & 97.5 \\
0Al600 & 33.207 & 0.225 & 36.87 & 97.5 \\
0Al900 & 33.237 & 0.223 & 37.2 & 97.8 \\
10Al300 & 35.827 & 0.399 & 20.94 & 91.8 \\
10Al600 & 33.361 & 0.217 & 38.19 & 86.1 \\
10Al900 & 33.347 & 0.209 & 39.72 & 86.1 \\
30Al300 & 35.978 & 0.340 & 24.58 & 74.1 \\
30Al600 & 35.870 & 0.265 & 31.68 & 69.0 \\
30Al900 & 33.407 & 0.272 & 30.5 & 69.0 \\
\hline
\end{tabular}




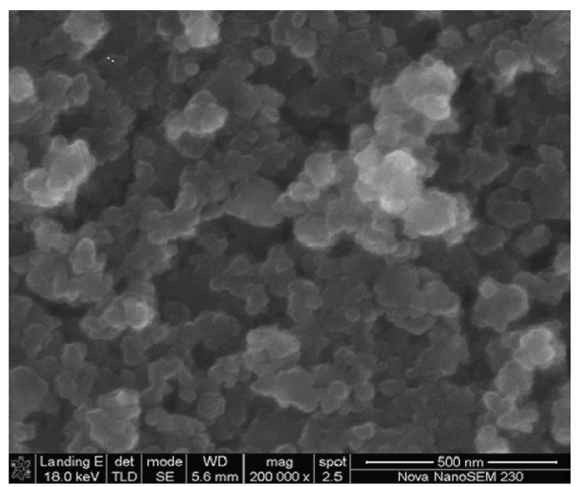

(a)

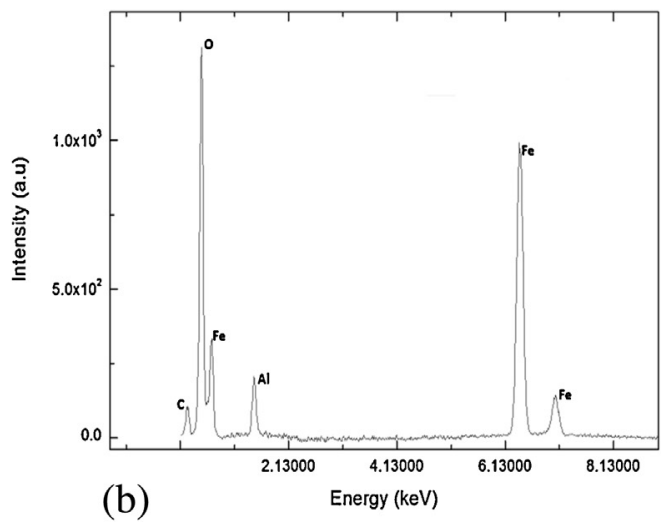

(b)

Fig. 2. a) Scanning electron microscopic image of $10 \mathrm{Al} 300 \mathrm{~b}$ ) EDX spectrum of $10 \mathrm{Al} 300$.

experiment that is 30\%. This is evidenced by the finding of [34], who observed peaks representing alumina at concentration higher than $30 \%$ for a temperature above $600^{\circ} \mathrm{C}$.

The average crystalline size was estimated using Debye Scherrer equation [43]

$\mathrm{D}=\frac{\mathrm{K} \lambda}{\beta \operatorname{Cos} \theta}$

where, $\mathrm{D}$ is crystallite size in $\mathrm{nm}, \mathrm{K}$ is the shape factor constant usually $0.9, \beta$ is the full width at half maximum(FWHM) in radians of $2 \theta, \lambda$ is the wavelength of the X-ray which is $0.15406 \mathrm{~nm}$ for $\mathrm{Cu}$ target $K \alpha_{1}$ radiation and $\theta$ is the Bragg's angle.

The calculated crystallite size is shown in Table 1 . The assynthesized powders ranged from 20 to $40 \mathrm{~nm}$. The average $\mathrm{Fe}_{2} \mathrm{O}_{3}$ contents in the three samples was roughly $98 \%, 89 \%$ and $71.5 \%$ for $0 \%, 10 \%$ and $30 \%$ addition of $\mathrm{Al}_{2} \mathrm{O}_{3}$ in the samples. The iron oxide content is consistent with the theoretical value expected in the samples. The difference from the theoretical value seemed to increase with increasing sintering temperature which could be accounted to the loss of the sample by carry over effect. As can be seen from Table 1, sample $10 \mathrm{Al} 300$ exhibited the smallest crystalline size and this sample was selected for the sorption experiment. Further characterization by SEM-EDX, TEM and FTIR to extract more information with respect to morphology, crystallite size and functional groups was also made on the selected nanosorbent named here after as Fe-Al binary oxide nanosorbent.

\subsection{SEM-EDX}

Scanning electron microscopy coupled with energy dispersive X-ray detector (SEM-EDX) was used to observe the morphology, particle size and composition of Fe-Al binary oxide nanosorbent. Sample $10 \mathrm{Al} 300$ was selected due to the smallest crystallite size obtained from XRD. SEM micrographs (Fig. 2a) corroborate the presence of homogenous particle size distribution with particle size below $100 \mathrm{~nm}$. X-ray energy dispersive analysis of the imaged area (Fig. 2 b) shows a relative concentration of aluminum and iron of $2.75 \%$ and $27.64 \%$, respectively.

\subsection{TEM}

Further confirmation of the actual particle size was obtained by TEM studies. Fig. 3 show representative images of $10 \mathrm{Al} 300 \mathrm{Fe}-\mathrm{Al}$ binary oxide nanosorbent. The material is formed by agglomerates of nanoparticles. The particle size distribution ranged from 8 to $20 \mathrm{~nm}$ with a maximum average crystallite size of $12 \mathrm{~nm}$ (Fig. 3b). These values agree less with those calculated from Debye-Scherrer formula $(20.9 \mathrm{~nm})$ which looses accuracy as the particle size
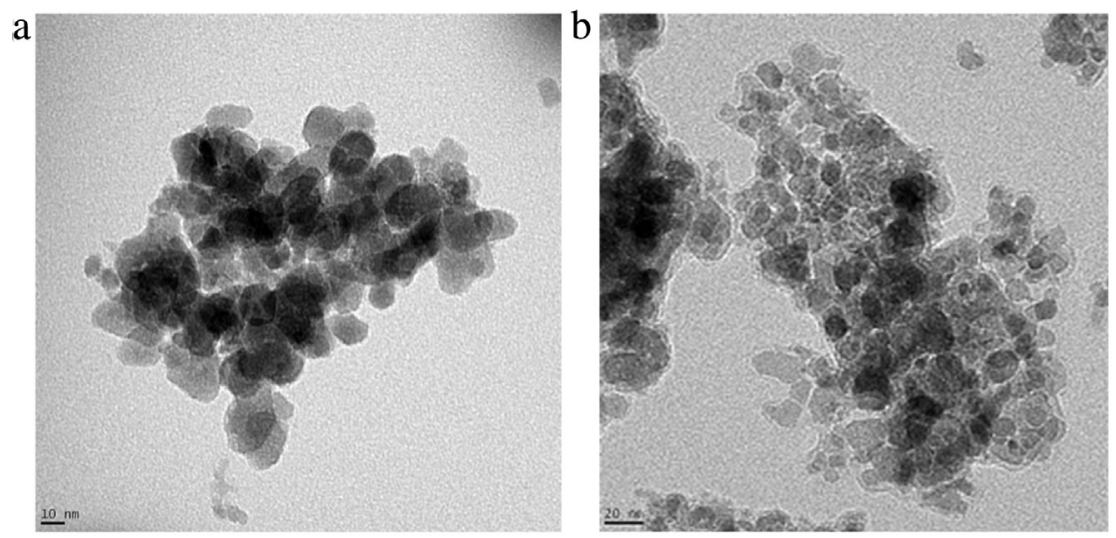

Size distribution for Iron Oxide nanopowder

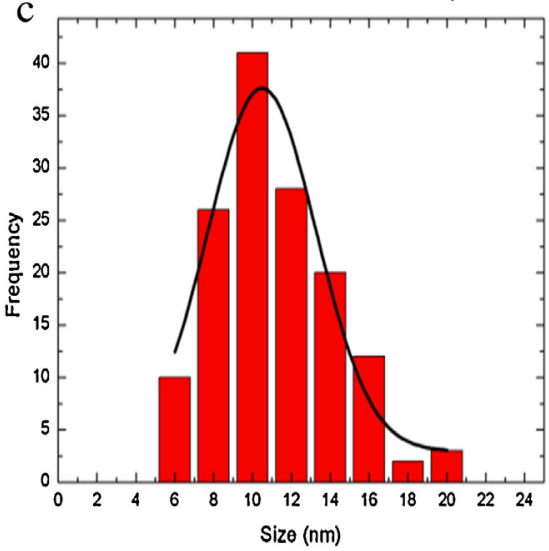

Fig. 3. TEM images (a \&b) and particle size distribution (c) of $10 \mathrm{Al} 300$. 


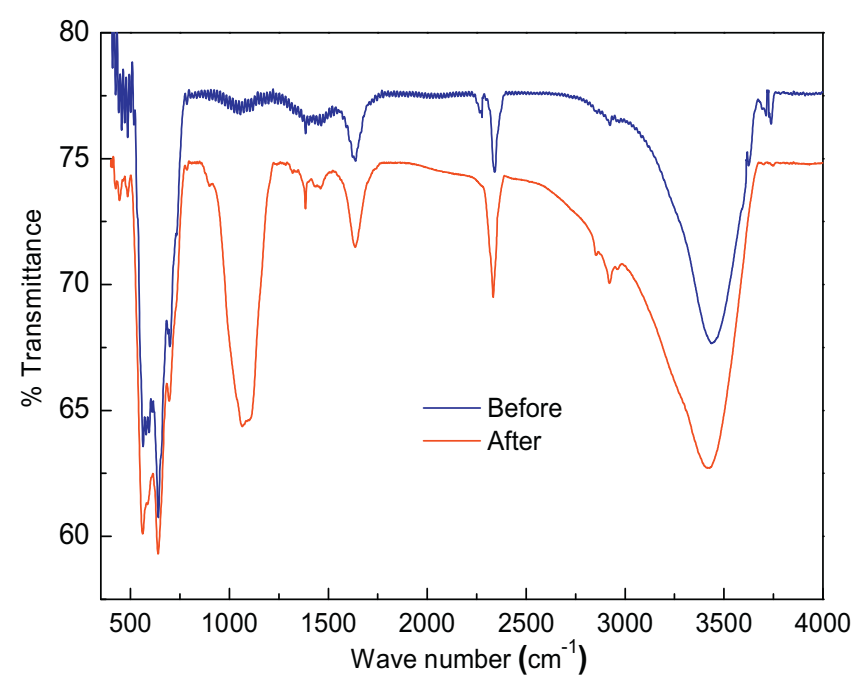

Fig. 4. FTIR spectrum of $10 \mathrm{Al} 30$ before and after phosphate sorption.

decreases. Nevertheless, electron microscopy studies confirmed that the as-synthesized material is in the nano-range.

\subsection{FTIR}

The IR spectra of 10Al300 display a number of peaks before and after phosphate adsorption (Fig. 4). The peaks observed in both cases are more or less similar. The absorption bands observed from 3400 to $3500 \mathrm{~cm}^{-1}$ represent $\mathrm{O}-\mathrm{H}$ stretching vibrations of adsorbed water molecules. The peaks observed at $1620 \mathrm{~cm}^{-1}$ can be ascribed to bending modes of water molecules. The absorption band at $2310 \mathrm{~cm}^{-1}$ is also common to both spectra which could be assigned to the adsorbed carbonate, because the adsorption tests were carried out open to the atmosphere. The absorption bands observed at $1340 \mathrm{~cm}^{-1}$ and $1114 \mathrm{~cm}^{-1}$ could be attributed to surface and multi-centered hydroxyl groups respectively. The $\mathrm{M}-\mathrm{O}$ stretching frequencies are observed at absorption bands of $660 \mathrm{~cm}^{-1}$ and $560 \mathrm{~cm}^{-1}$. For a spectrum after phosphate adsorption additional peak at $1078 \mathrm{~cm}^{-1}$ was observed owing to the P-O stretching modes indicating the adsorption of phosphate on the surface of the nanosorbent [29]

\subsection{Effect of ionic strength}

The phosphate adsorption mechanism of Fe-Al binary oxide nanosorbent was investigated by evaluating the ionic strength effect on the adsorption behavior. Fig. 5 demonstrates that the

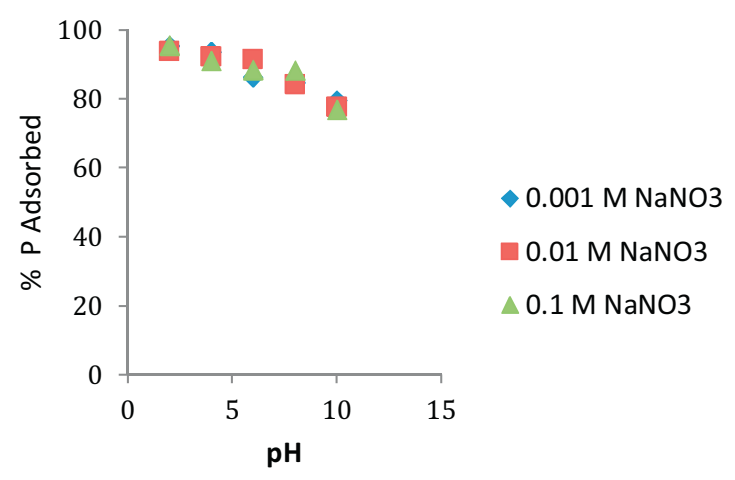

Fig. 5. Effect of ionic strength on phosphate sorption by Fe-Al binary oxide nanosorbent (initial phosphate concentration $5 \mathrm{mg} / \mathrm{L}$ and adsorbent load $0.1 \mathrm{~g} / \mathrm{L}$ ). phosphate adsorption showed no significant change on phosphate adsorption as the ionic strength increased from 0.001 to $0.1 \mathrm{~mol}$ $\mathrm{L}^{-1}$. Moreover, at $\mathrm{pH} 6$ and 8 , increasing phosphate sorption was evidenced with increase in ionic strength. It is well known that anions adsorbed by outer-sphere association are strongly sensitive to ionic strength where as anions adsorbed by inner-sphere association either show little sensitivity to ionic strength or greater phosphate adsorption with increasing ionic strength [31]. Based on this finding, it can be concluded that phosphate anions may be specifically adsorbed on the Fe-Al binary oxide nanosorbent via forming inner-sphere surface complexes.

\subsection{Optimum conditions}

Batch mode of adsorption was conducted to optimize parameters such as adsorbent dose, speed of agitation, contact time and initial phosphate concentration and the respective optimum values were found to be $\mathrm{pH} 4$; adsorbent dose $0.1 \mathrm{~g}$; agitation speed $140 \mathrm{rpm}$; contact time $12 \mathrm{~h}$ and initial phosphate concentration $20 \mathrm{mg} / \mathrm{L}$ (data presented on the supplementary information Figs. S1-S4). Here we report the effect of $\mathrm{pH}$ as it is one of the most important factors that influences most adsorption processes. $\mathrm{pH}$ effect on the extent of phosphate adsorption onto Fe-Al binary oxide nanosorbent was investigated by varying the $\mathrm{pH}$ from 2 to 9 keeping the other parameters constant. The result obtained as such is illustrated in Fig. 6. In general, the sorption capacity was found to be above $97 \%$ up to $\mathrm{pH}=7$, the maximum being $99.2 \%$ at $\mathrm{pH}=4$, indicating that the Fe-Al binary oxide nanosorbent can work with a relatively wide range of $\mathrm{pH}(\mathrm{pH}=2-7)$. However, a decreasing trend in phosphate sorption was observed when the $\mathrm{pH}$ value exceeds 4 the decline being significant beyond $\mathrm{pH}=7$ [43]. Thus phosphate sorption would become more favorable at a lower $\mathrm{pH}$ than at a higher $\mathrm{pH}$. The phosphate dissociation equilibrium in aqueous solution is dependent on $\mathrm{pH}$ which could be represented as:

$\mathrm{H}_{3} \mathrm{PO}_{4} \stackrel{\mathrm{pk} 1}{\rightleftarrows} \mathrm{H}_{3} \mathrm{PO}_{4}{ }^{-}+\mathrm{H}^{+} \stackrel{\mathrm{pk} 2}{\rightleftarrows} \mathrm{H}_{3} \mathrm{PO}_{4}{ }^{2-}+\mathrm{H}^{+} \stackrel{\mathrm{pk} 3}{\rightleftarrows} \mathrm{PO}_{4}{ }^{3-}+\mathrm{H}^{+}$

Where $\mathrm{pK}_{1}=2.15, \mathrm{pK}_{2}=7.2$ and $\mathrm{pK}_{3}=12.33$ respectively. In the $\mathrm{pH}$ range investigated $(\mathrm{pH}=2-9)$, negatively charged $\mathrm{H}_{2} \mathrm{PO}_{4}{ }^{-}$and $\mathrm{H}_{2} \mathrm{PO}_{4}{ }^{2-}$ are the dominated species of phosphate. It can be assumed that the $\mathrm{H}_{2} \mathrm{PO}_{4}{ }^{-}$ions are the predominant species in the $\mathrm{pH}$ range of 3-6, while the $\mathrm{HPO}_{4}{ }^{2-}$ ions appear to be the more dominant species at higher $\mathrm{pH}$ values. Reports indicate that the

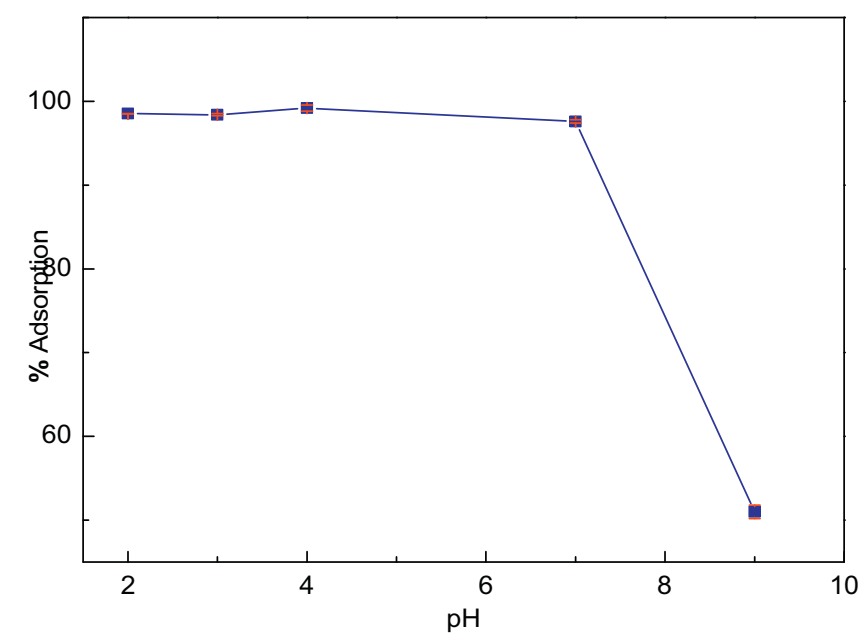

Fig. 6. Effect of $\mathrm{pH}$ on the removal efficiency of the nano sized sorbent for phosphate (Phosphate concentration $=30 \mathrm{mg} / \mathrm{L}$, adsorbent dose $=0.1 \mathrm{~g}$; agitation speed $=120 \mathrm{rpm}$ and contact time $=24 \mathrm{~h}$ ). 
Table 2

Phosphate adsorption isotherms on Fe-Al binary oxide nanosized adsorbent.

\begin{tabular}{|c|c|c|c|c|c|c|}
\hline Initial concentration $(\mathrm{Co}) \mathrm{mg} / \mathrm{L}$ & $\begin{array}{l}\text { Dose of adsorbent } \\
(\mathrm{g})\end{array}$ & Final concentration $(\mathrm{Ce}) \mathrm{mg} / \mathrm{L}$ & Adsorption capacity) ( $\left.\mathrm{q}_{\mathrm{e}}\right) \mathrm{mg} / \mathrm{g}$ & $\mathrm{C}_{\mathrm{e}} / \mathrm{q}_{\mathrm{e}}$ & $\log C_{e}$ & $\log \mathrm{q}_{\mathrm{e}}$ \\
\hline 20 & 0.1 & 0.028 & 4.99 & 0.0056 & -1.55 & 0.698 \\
\hline 30 & 0.1 & 0.337 & 7.41 & 0.045 & -0.472 & 0.869 \\
\hline 50 & 0.1 & 3.79 & 11.55 & 0.328 & 0.578 & 1.063 \\
\hline 100 & 0.1 & 40.44 & 14.89 & 2.72 & 1.61 & 1.170 \\
\hline 150 & 0.1 & 86.21 & 15.95 & 5.4 & 1.94 & 1.200 \\
\hline 200 & 0.1 & 134.5 & 16.38 & 8.21 & 2.13 & 1.210 \\
\hline
\end{tabular}

$\mathrm{H}_{2} \mathrm{PO}_{4}{ }^{-}$species are more easily adsorbed on metal (hydr) oxide surfaces than other species $[41,46]$. Low $\mathrm{pH}$ is beneficial for the surface protonation of the metal oxide. Increased protonation would increase the positively charged sites, enlarging the attraction force existing between the metal oxide surface and the negatively charged anions. Hence, higher adsorption capacity of phosphate on the sorbent was observed in the low $\mathrm{pH}$ region. The significant decrease in phosphate adsorption above $\mathrm{pH} 7$ could be attributed to a change in surface charge caused by the nanosized mixed oxide adsorbent which is actually becoming more negative at higher $\mathrm{pH}$ values. This process would therefore result in the electrostatic repulsion between the exchange sites and the incoming phosphate ions [43-47]. As a result, phosphate adsorption dropped remarkably.

\subsection{Adsorption equilibrium}

Experiments on phosphate adsorption isotherm were conducted with different initial concentration of phosphate at room temperature keeping all other parameters at optimum conditions. The results of phosphate adsorption isotherm on the nanosized adsorbent are illustrated in Table 2.

From the linear Langmuir adsorption model,

$$
\frac{C_{e}}{q_{e}}=\frac{1}{Q_{0} b}+\frac{C_{e}}{Q_{0}}
$$

The plot $\mathrm{C}_{\mathrm{e}} / \mathrm{q}_{\mathrm{e}}$ vs. $\mathrm{C}_{\mathrm{e}}$ yields a straight line with a slope $1 / \mathrm{Q}_{\mathrm{o}}$ and an intercept $1 / \mathrm{Q}_{0} \mathrm{~b}$. According to Fig. 7a, the slope can be read as 0.061 , which reflects a $Q_{0}$ value of $16.39 \mathrm{mg} / \mathrm{g}$. Furthermore, the plot has intercept of 0.0867 which in turn gives $b$ value of 0.7 . The feasibility of the isotherm can be tested by calculating the dimensionless constant, $\mathrm{R}_{\mathrm{L}}$ expressed as:

$R_{L}=\frac{1}{1+b C_{o}}$

As can be seen in Table $3, \mathrm{R}_{\mathrm{L}}$ values are in between 0 and 1 indicating a favorable adsorption. This means that phosphate ions in solution have tended to be adsorbed on the Fe-Al binary oxide nanosorbent. The Freundlich equation is an empirical expression that encompasses the heterogeneity of the surface and the exponential distribution of sites and their energies. The linearized form of the equation is:

$\log q_{e}=\log k_{f}+\frac{1}{n} \log C_{e}$

Plotting $\log \mathrm{q}_{\mathrm{e}}$ versus $\log \mathrm{C}_{\mathrm{e}}$ provides a straight line with a slope of $1 / \mathrm{n}$ and intercept of $\log \mathrm{K}_{\mathrm{f}}$. According to Fig. $7 \mathrm{~b}$, the slope value of 0.1406 could be related to the ' $1 / \mathrm{n}$ ' in the Freundlich's equation. The intercept $\left(\log K_{f}\right)$ could be rearrenged to give value of $K_{f}$ as 8.63. Therfore, a Freundlich's equation for the adsopriton process has been developed as:

$q_{e}=8.63 C^{0.1406}$

The value of $1 / \mathrm{n}$ lying between 0 and 1 , which in this case is 0.1406 , and the n value lying between 1 and 10 , which in this case is 7.11, indicate a favorable condition for adsorption [39]. The Langmuir's and Freundlich's curves were interpreted with respect to correlation coefficient $\left(\mathrm{R}^{2}\right)$, a statistical measure of how well the regression line approximates the real data point (Table 4 ). In this study, the sorption isotherm of the Fe-Al binary oxide nanosorbent showed better fit to both isotherms though the value of $R^{2}$ is relatively higher for Langmuir's equation than the Freundlich (i.e.
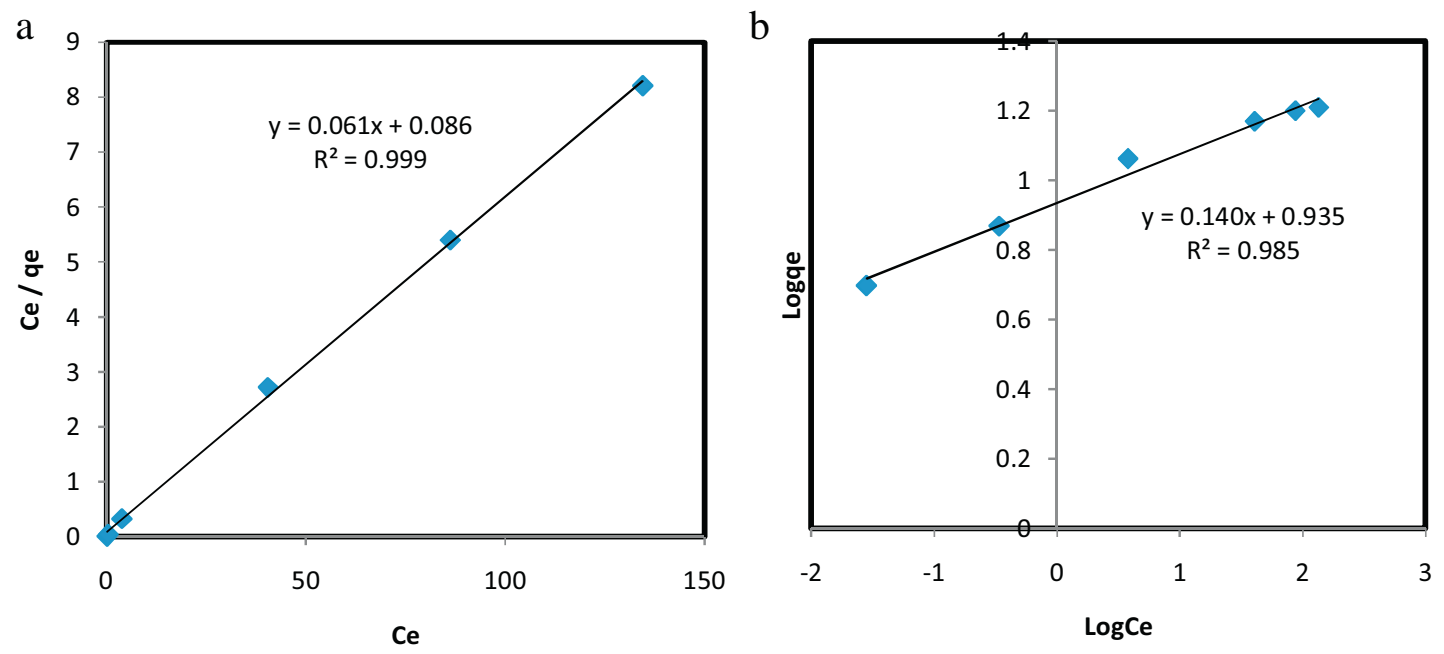

Fig. 7. a) Langmuir adsorption isotherms for phosphate adsorption and b) Freundlich adsorption isotherm for phosphate adsorption. 
Table 3

$\mathrm{R}_{\mathrm{L}}$ values for phosphate adsorption at different concentration.

\begin{tabular}{lllllll}
\hline Initial concentration $(\mathrm{mg} / \mathrm{L}$ & 20 & 30 & 50 & 100 & 150 & 200 \\
\hline $\mathrm{R}_{\mathrm{L}}$ & 0.066 & 0.045 & 0.027 & 0.014 & 0.009 & 0.007 \\
\hline
\end{tabular}

\section{Table 4}

Langmuir and Freundlich constants for phosphate removal onto Fe-Al binary oxide. Nanoadsorbent

\begin{tabular}{lllllll}
\hline \multicolumn{2}{l}{ Langmuir isotherm model } & & \multicolumn{3}{l}{ Freundlich isotherm model } \\
\hline $\mathrm{Q}^{0}$ & $\mathrm{~b}$ & $\mathrm{R}_{\mathrm{L}}$ & $\mathrm{R}^{2}$ & $\mathrm{~K}_{\mathrm{f}}$ & $1 / \mathrm{n}$ & $\mathrm{R}^{2}$ \\
16.39 & 0.7 & 0.066 & 0.9992 & 8.63 & 0.1406 & 0.985 \\
\hline
\end{tabular}

0.999 versus 0.985 , respectively). This indicates that each sites of the adsorbent can accommodate one molecule of phosphate ion or can be characterized by supporting surfaces of different affinity (heterogeneity of surfaces which may be from doping of aluminum). Comparison of the maximum adsorption capacity of the Fe-Al binary oxide with other binary or ternary systems previously reported showed that the as-synthesized nanosorbent exhibited moderate sorption capacity (Table 5).

\subsection{Selectivity of phosphate adsorption}

Fig. 8 shows the influence of various anions on phosphate removal efficiency of Fe-Al binary oxide nanosorbent. At optimum condition, the adsorption efficiency was found to be $99.86 \%$. In line with this, Fig. 8 shows that the adsorbent is still efficient in removing phosphate from aqueous system. It is only in the presence of fluoride ion that the adsorption efficiency decreased down to $97.68 \%$. Evidence has been reported demonstrating the interaction between fluoride and nano alumina moieties is a feasible process [48]. Such interaction might be the reason for the decrease in adsorption efficiency of nano-sized Fe-Al binary oxide nanosorbent toward phosphate ion in the presence of fluoride.

\subsection{Thermodynamic study}

The thermodynamic parameters such as change in standard free energy $(\Delta \mathrm{G})$, enthalpy $(\Delta \mathrm{H})$ and entropy $(\Delta \mathrm{S})$ can be calculated by using the following equation:

$\ln K_{c}=\frac{\Delta S}{R}-\frac{\Delta H}{T R}$

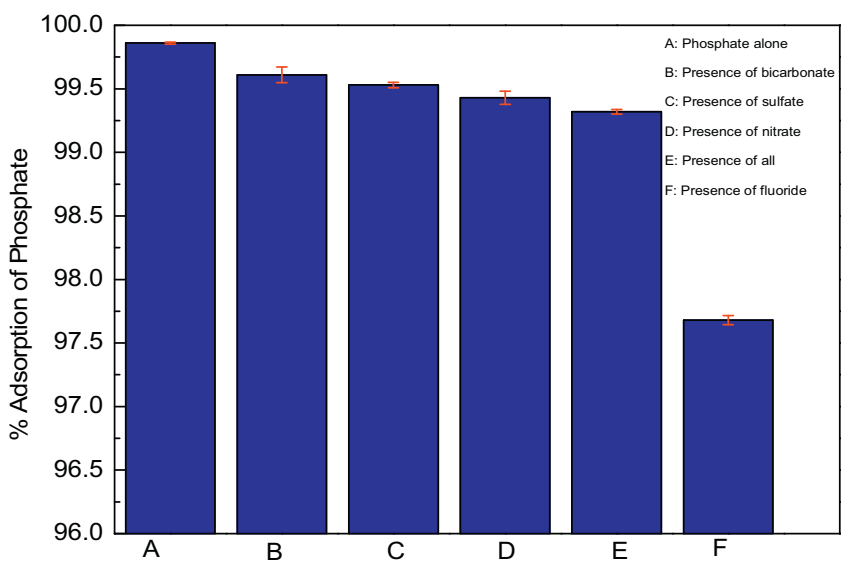

Fig. 8. Effect of co-existing anions on phosphate removal.

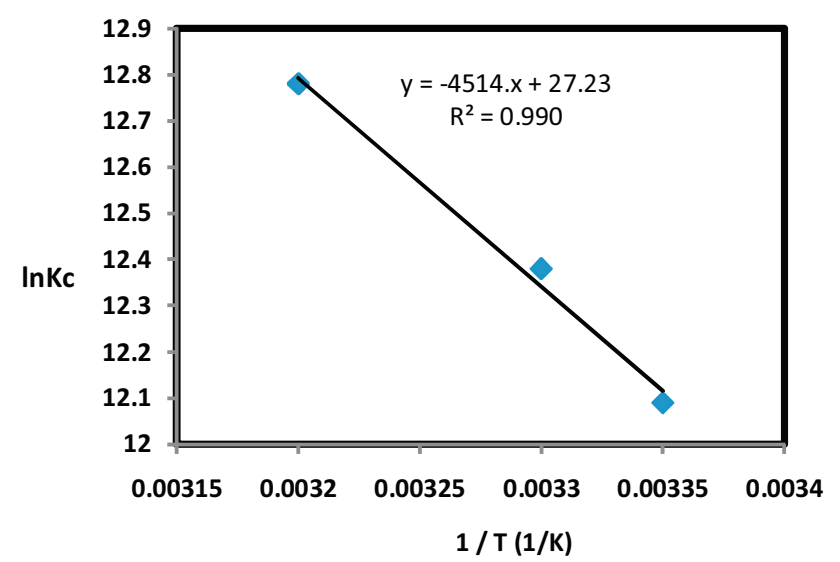

Fig. 9. Plot of $\operatorname{lnKc}$ vs $\mathrm{T}^{-1}$ for phosphate adsorption onto Fe-Al binary oxide nanosorbent $(\mathrm{pH}=4$, dose $=0.1 \mathrm{~g}$, Agitation speed $=140 \mathrm{rpm}$, Contact time $=12 \mathrm{~h}$, $\mathrm{Co}=20 \mathrm{mg} / \mathrm{L})$.

$$
\Delta \mathrm{G}=\Delta H-T \Delta S
$$

where $R(8.314 \mathrm{~J} / \mathrm{mol} \mathrm{K})$ is the gas constant, $T(K)$ is the absolute temperature and $\mathrm{Kc}$ is the standard thermodynamic equilibrium constant defined by $\mathrm{q}_{\mathrm{e}} / \mathrm{Ce}$. By plotting the graph of $\ln \mathrm{Kc}$ versus $\mathrm{T}^{-1}$ (Fig. 9), the value of $\Delta H$ and $\Delta S$ can be estimated from the slopes and intercept. $\Delta \mathrm{H}$ and $\Delta \mathrm{S}$ have been calculated from slope and

Table 5

Comparison of maximum phosphate adsorption capacities for different binary/ternary metal oxide adsorbents.

\begin{tabular}{|c|c|c|c|c|}
\hline Adsorbents & Crystallinity & Optimum pH & Maximum Sorption Capacity mg/g & References \\
\hline Fe-Mn & Amorphous & 5.6 & 36 & [1] \\
\hline $\mathrm{Fe}-\mathrm{Zr}$ & Crystalline & 4 & 13.65 & [18] \\
\hline $\mathrm{Fe}-\mathrm{Al}$ & Amorphous & 3 & 61.5 & [28] \\
\hline $\mathrm{Fe}-\mathrm{Cu}$ & Amorphous & 7 & 35.2 & [29] \\
\hline $\mathrm{Fe}-\mathrm{Cu}$ & Amorphous & 5.0 & 39.8 & [29] \\
\hline Fe-Mn & Amorphous & 5 & 123 & [30] \\
\hline Fe-Ti & Amorphous & 6.8 & 35.4 & [31] \\
\hline Fe-Zr (magnetite) & Amorphous & 3 & 39.1 & [33] \\
\hline Fe-Al-Mn & Amorphous & 6.8 & 48.3 & [49] \\
\hline $\mathrm{Ce}-\mathrm{Zr}$ & Crystalline & $2-6$ & 112.3 & [50] \\
\hline $\mathrm{Fe}-\mathrm{Cr}$ & - & 4 & 6.5 & [51] \\
\hline Ti-Fe & Crystalline & 5 & 30.3 & [52] \\
\hline Fe-Mg-La & Amorphous & 6 & 415.2 & {$[53]$} \\
\hline $\mathrm{Fe}-\mathrm{Al}$ & Crystalline & 4 & 16.4 & Present Study \\
\hline
\end{tabular}



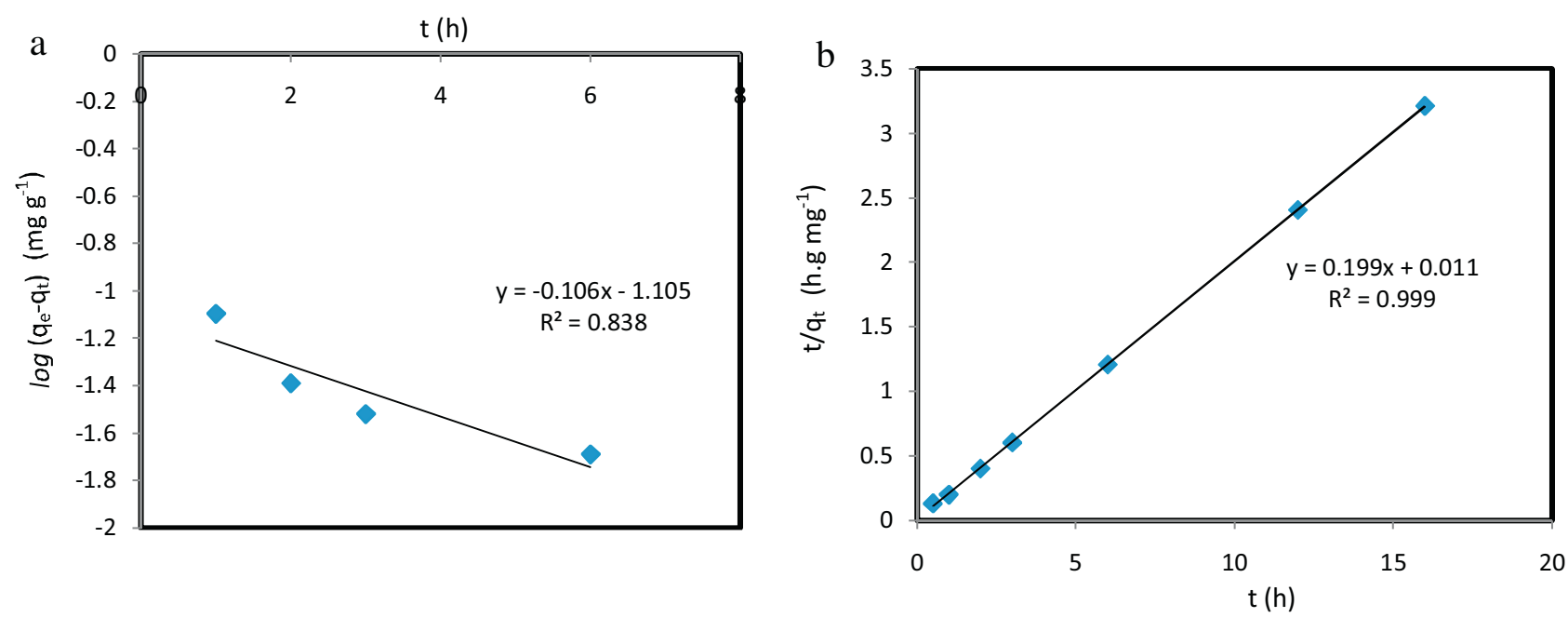

Fig. 10. Pseudo first order kinetics (a) and (b) Pseudo second order kinetics for phosphate adsorption on to Fe-Al binary oxide nanoadsorbent.

intercept of Fig. 8 as $+37.53 \mathrm{KJ} / \mathrm{mol}$ and $+226.39 \mathrm{~J} / \mathrm{mol} \mathrm{K}$ respectively (Table 6).

The negative value of $\Delta G$ and positive value of $\Delta H$ obtained indicated that the phosphate adsorption process is a spontaneous and endothermic process. The decrease in $\Delta \mathrm{G}$ with increase in temperature indicated more efficient adsorption at higher temperature $(308 \mathrm{~K})$. The positive value of $\Delta \mathrm{S}$ suggested that the increased randomness at the solid/solution interface occur in the internal structure of phosphate removal onto nanosized mixed oxide sorbent.

\subsection{Kinetic study}

The rate of the phosphate sorption onto Fe-Al binary oxide nanosorbent was studied in batch experiments at optimized values of the parameters. The kinetic data of phosphate adsorption was fitted with pseudo-first-order and pseudo-second-order models. The obtained kinetic model parameters by linear regressions are given in Fig. 10a and b and Table 7. It was found that the kinetic data at the two initial phosphate concentrations were fitted better by the pseudo-second-order adsorption kinetic rate model, indicating that chemisorption or chemical bonding between adsorbent active sites and phosphate might dominate the adsorption process [1].

\subsection{Desorption study}

Phosphate desorption was conducted by using the residual solids retained on the filter paper. Desorption of Phosphate from phosphate loaded adsorbents increased with increasing initial $\mathrm{pH}$ (Fig. 11). When the $\mathrm{pH}$ value is 2 the desorbed value of phosphate could not be detected. The desorbability of phosphate increased with increasing $\mathrm{pH}$ value. The results of this finding indicated that

Table 6

Thermodynamic parameters for phosphate adsorption on to $\mathrm{Fe}-\mathrm{Al}$ binary oxide nano-adsorbent.

\begin{tabular}{llll}
\hline $\mathrm{T}(\mathrm{K})$ & $\Delta \mathrm{G}(\mathrm{KJ} / \mathrm{mol})$ & $\Delta \mathrm{H}(\mathrm{KJ} / \mathrm{mol})$ & $\Delta \mathrm{S}(\mathrm{J} / \mathrm{mol} \mathrm{K})$ \\
\hline 298 & -29.93 & +37.53 & +226.39 \\
303 & -31.06 & & \\
308 & -32.19 & & \\
\hline
\end{tabular}

phosphate adsorption onto the nanosized adsorbent is not completely reversible and phosphate can be desorbed from the adsorbent by adjusting the $\mathrm{pH}$ value. The percent desorbed, however, in our case was relatively lower than previous reports $[9,30]$, perhaps because we employed relatively lower volume of $\mathrm{NaOH}$ to effect the desorption.

\section{Conclusions}

The nanosized iron aluminum mixed oxide was tested to remove phosphate ions from aqueous solutions. The X-ray diffraction pattern indicated that all the as-synthesized materials are in the nano range whose particle size increased with increasing temperature. Doping of aluminum was found to delay the crystallinity of the as-synthesized compounds. The smallest particle size $(20.94 \mathrm{~nm})$, was found to be the $10 \%$ aluminum doped iron oxide calcinated at $300{ }^{\circ} \mathrm{C}(10 \mathrm{Al} 300)$. The mechanism of phosphate adsorption was studied both from macroscopic and microscopic perspectives and both methods support the chemisorptions process as the dominant mechanism of adsorption. The effect of $\mathrm{pH}$ on the adsorption of phosphate showed that removal efficiency decreased with increasing $\mathrm{pH}$. The optimum $\mathrm{pH}$ for the removal of phosphate was found to be 4 . Having all the parameters optimized, this study has shown $99.86 \%$ efficiency of phosphate ion removal from aqueous solution. The adsorption processes were fitted to both Langmuir and Freundlich isotherms with the latter being higher for a wide range of adsorbate concentrations. Values of the equilibrium parameter $\left(R_{L}\right)$ from Langmuir isotherm and $n$ values from the Freundlich isotherm have indicated that the adsorption process is favorable. Thermodynamic study on the phosphate sorption process revealed that the phosphate sorption process was found to be spontaneous and endothermic. Furthermore, Phosphate desorbability was observed to increase with

Table 7

Kinetic parameters for phosphate sorption onto the Fe-Al binary oxide nanoadsorbent.

\begin{tabular}{llllll}
\hline \multicolumn{2}{l}{ First Order Model } & \multicolumn{5}{l}{ Second Order Model } \\
\hline$K_{1}\left(\mathrm{~h}^{-1}\right)$ & $\mathrm{q}_{\mathrm{e}}\left(\mathrm{mg} \mathrm{g}^{-1}\right)$ & $\mathrm{R}^{2}$ & $k_{2}\left(\mathrm{gh}^{-1} \mathrm{mg}^{-1}\right)$ & $\mathrm{q}_{\mathrm{e}}\left(\mathrm{mgg}^{-1}\right)$ & $\mathrm{R}^{2}$ \\
0.244 & 0.078 & 0.838 & 0.36 & 5.025 & 0.999 \\
\hline
\end{tabular}




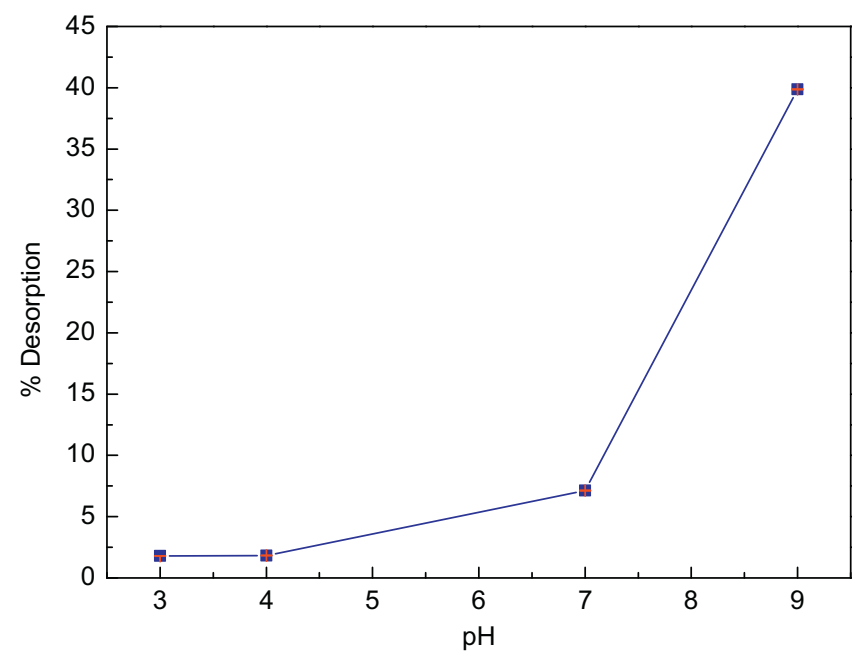

Fig. 11. Effect of $\mathrm{pH}$ on desorption of phosphate at varied $\mathrm{pH}$.

increasing $\mathrm{pH}$ indicating the relatively favorable conditions for recyclability of the process at higher $\mathrm{pH}$ values.

\section{Acknowledgements}

The financial support from Research and Extension Office of Haramaya University, the School of Graduate Studies and Chemistry Department of HU are acknowledged. University of Cape Town is also acknowledged for running the XRD of our samples.

\section{Appendix A. Supplementary data}

Supplementary data associated with this article can be found, in the online version, at http://dx.doi.org/10.1016/j.jece.2016.04.023.

\section{References}

[1] G. Zhang, H. Liu, R. Liu, J. Qu, Removal of phosphate from water by Fe-Mn binary oxide adsorbent, J. Colloids Interface Sci. 335 (2009) 168-174.

[2] X.J. Wang, S.Q. Xia, L. Chen, J.F. Zhao, N.J. Renault, J.M. Chovelon, Nutrients removal municipal wastewater by chemical precipitation in a moving bed biofilm reactor, Process Biochem. 41 (2006) 824-828.

[3] A. Ohmen, P.C. Lemos, G. Carvallho, Z.G.J. Yuan Keller, L.L. Blackal, M.A.M. Reis, Advances in enhanced biological phosphorous removal: from micro and macro scale, Water Res. 41 (2007) 2271-2300.

[4] Y. Fukumoto, K. Haga, Advanced treatment of swine wastewater by electrodialysis with a tubular ion exchange membrane, Anim. Sci. J. 75 (2004) 479485.

[5] N.I. Chubar, V.A. Kanibolotskyy, V.V. Strelko, G.G. Gallios, V.F. Samanidou, T.O. Shaposhnikova, V.G. Milgrandi, I.Z. Zhuravlve, Adsorption of phosphate on novel inorganic ion exchangers, Colloids Surf. A 255 (2005) 55-63.

[6] L.E. de-Bashan, Y. Bashan, Recent advances in removing phosphorus from wastewater and its future use as fertilizers (1997-2003), Water Res. 38 (2004) $4222-4246$.

[7] H. Yin, Y. Yun, Y. Zhang, C. Fan, Phosphate removal from wastewater by a naturally occurring, calcium-rich sepiolite, J. Hazard. Mater. 198 (2011) 362 369.

[8] Y. Li, C. Liu, Z. Luan, X. Peng, C. Zhu, Z. Chen, Z. Zhang, J. Fan, Z. Jia, Phosphate removal from aqueous solutions using raw and activated carbon and fly ash, J. Hazard. Mater. B 137 (2006) 374-383.

[9] G. Li, S. Gao, G. Zhang, X. Zhang, Enhanced adsorption of phosphate from aqueous solution by nanostructured iron(III)-copper(II) binary oxides, Chem. Eng. J. 235 (2014) 124-131.

[10] S. Karaca, A. Gurses, M. Edjer, M. Acikyildiz, Adsorptive removal of phosphate from aqueous solutions using raw and calcinated dolomite, J. Hazard. Mater. B 128 (2006) 273-279.

[11] K. Karageorgiou, M. Paschalis, G.N. Anastassakis, Removal of phosphate species from solutions by adsorption onto calcite used as natural adsorbent, J. Hazard. Mater. A139 (2007) 447-452.

[12] F. Gérard, Clay minerals, iron/aluminum oxides, and their contribution to phosphate sorption in soils-a myth revisited, Geoderma 262 (2016) 213-226.
[13] W. Huang, S. Wang, Z. Zhu, L. Li, X. Yao, V. Rudolph, F. Haghseresht, Phosphate removal from wastewater using red mud, J. Hazard. Mater. 158 (2008) 35-42.

[14] J. Yan, D.W. Kirk, C.Q. Jia, X. Liu, Sorption of aqueous phosphorus onto bituminous and lignitous coal ashes, J. Hazard. Mater. 148 (2007) 395-401.

[15] A.O. Babatunde, Y.Q. Zhao, Equilibrium and kinetic analysis of phosphorus adsorption from aqueous solution using waste alum sludge, J. Hazard. Mater. 184 (2010) 746-752.

[16] A.H. Caravelli, E.M. Contreras, N.E. Zaritzky, Phosphorus removal in batch systems using ferric chloride in the presence of activated sludges, J. Hazard. Mater. 172 (2010) 199-208.

[17] S. Wang, C. Cheng, Y. Tzou, R. Liaw, T. Chang, J.H. Chen, Phosphate removal from water using lithium intercalated gibbsite, J. Hazard. Mater. 147 (2007) 205212.

[18] F. Long, J. Gong, G.M. Zeng, L. Chen, X. Wang, J. Deng, Q. Niu, H. Zhang, X. Zhang, Removal of phosphate from aqueous solution by magnetic Fe-Zr binary oxide, Chem. Eng. J. 171 (2011) 448-455.

[19] H. Liu, X. Sun, C. Yin, C. Hu, Removal of phosphate by mesoporous $\mathrm{ZrO}_{2}$, J. Hazard. Mater. 151 (2008) 616-622.

[20] O.R. Harvey, R.D. Rhue, Kinetics and energetic of phosphate sorption in a multicomponent $\mathrm{Al}(\mathrm{III})-\mathrm{Fe}(\mathrm{III})$ hydr (oxide) sorbent system, J. Colloids Interface Sci. 322 (2008) 384-393.

[21] J. Lalley, C. Han, X. Li, D.D. Dionysiou, M.N. Nadagouda, Phosphate adsorption using modified iron oxide-based sorbents in lake water: kinetics, equilibrium, and column tests, Chem. Eng. J. 284 (2016) 1386-1396.

[22] S. Mustafa, M.I. Zaman, S. Khan, pH effect on phosphate sorption by crystalline $\mathrm{MnO}_{2}$, J. Colloid Interface Sci. 301 (2006) 370-375.

[23] Y. Liu, X. Sheng, Y. Dong, Y. Ma, Removal of high-concentration phosphate by calcite: effect of sulfate and pH, Desalination 289 (2012) 66-71.

[24] S. Mustafa, M.I. Zaman, S. Khan, pH effect on phosphate sorption by crystalline $\mathrm{MnO}_{2}$, J. Colloid. Interface Sci. 301 (2006) 370-375.

[25] S. Mustafa, M.I. Zaman, S. Khan, Temperature effect on the mechanism of phosphate anions sorption by $\beta-\mathrm{MnO}_{2}$, Chem. Eng. J. 141 (2008) 51-57.

[26] H.A.B. Potter, R.N. Yong, Influence of iron/aluminum ratio on the retention of lead and copper by amorphous iron-aluminum oxides, Appl. Clay Sci. 14 (1999) $1-26$.

[27] D. Dong, Y.M. Nelson, L.W. Lion, M.L. Schuler, W.C. Ghiorse, Adsorption of Pb and Cd onto metal oxides and organic material in natural surface coatings as determined by selective extractions: new evidence for the importance of Mn and Fe oxides, Water Res. 34 (2000) 427-436.

[28] A.F. de Sousa, T.P. Braga, E.C. Chagas Gomes, A. Valentini, E. Longhinotti, Adsorption of phosphate using mesoporous spheres containing iron and aluminum oxide, Chem. Eng. J. 210 (2012) 143-149.

[29] G. Li, S. Gao, G. Zhang, X. Zhang, Enhanced adsorption of phosphate from aqueous solution by nanostructured iron(III)-copper(II) binary oxides, Chem. Eng. J. 235 (2014) 124-131.

[30] J. Lu, H. Liu, X. Zhao, W. Jefferson, F. Cheng, J. Qu, Phosphate removal from water using freshly formed Fe-Mn binaryoxide: adsorption behaviors and mechanisms, Colloids Surf. A 455 (2014) 11-18.

[31] J. Lu, D. Liu, J. Hao, G. Zhang, B. Lu, Phosphate removal from aqueous solutions by a nano-structured Fe?Ti bimetal oxide sorbent, Chem. Eng. Res. Des. 93 (2015) 652-661.

[32] L. Chen, B.Y. He, S. He, T.J. Wang, C.L. Su, Y. Jin, Fe-Ti oxide nanosorbent synthesized by co-precipitation for fluoride removal from drinking water and its adsorption mechanism, Powder Technol. 227 (2011) 3-8.

[33] A. Sarkar, S.K. Biswas, P. Pramanik, Design of a new nanostructure comprising mesoporous $\mathrm{ZrO}_{2}$ shell and magnetite core $\left(\mathrm{Fe}_{3} \mathrm{O}_{4} @ \mathrm{mZrO}_{2}\right)$ and study of its phosphate ion separation efficiency, J. Mater. Chem. 20 (2010) 4417-4424.

[34] F.B. Li, X.Z. Li, C.S. Liu, T.X. Liu, Effect of alumina on photocatalytic activity of iron oxides for bisphenol A, J. Hazard. Mater. 149 (2007) 199-207.

[35] E.A. El-Sharkawy, S.A. El-Hakam, S.E. Samra, Effect of thermal treatment on the various properties of iron(III)-aluminum(III) coprecipitated hydroxide system, Mater. Lett. 42 (2000) 318-331.

[36] J.Y. Park, Y. Lee, P.K. Khanna, K. Jun, J.W. Bae, Y.H. Kim, Alumina-supported iron oxide nanoparticles as Fischer-Tropsch catalysts: effect of particle size of iron oxide, J. Mol. Catal. A 323 (2010) 84-90.

[37] K. Gupta, S. Bhattacharya, D. Chattopadhyay, A. Mukhopadhyay, H. Biswas, J. Dutta, N. Ranjan Ray, U.C. Ghosh, Ceria associated manganese oxide nanoparticles: synthesis, characterization and arsenic(V) sorption behavior, Chem. Eng. J. 172 (2011) 219-229.

[38] F. Gulshan, Y. Kameshima, A. Nakajima, K. Okada, Preparation of alumina-iron oxide compounds by gel evaporation method and its simultaneous uptake properties for $\mathrm{Ni}^{2+}, \mathrm{NH}_{4}{ }^{+}$and $\mathrm{H}_{2} \mathrm{PO}_{4}{ }^{-}$, J. Hazard. Mater. 169 (2009) 697-702.

[39] R.L. Parfitt, R.J. Atkinson, Phosphate adsopriotn on goethite $(\alpha-\mathrm{FeOOH})$, Nature 264 (1976) 740-742.

[40] Y.S. Ho, Review of second-order models for adsorption systems, J. Hazard. Mater. 136 (2006) 681-689.

[41] L.A. Rodrigues, M.L.C. da silva, An investigation of phosphate adsorption from aqueous solution onto hydrous niobium oxide prepared by co-precipitation method, J. Colloids Surf. A. 334 (2009) 191-196.

[42] J. Kenkil, Analytical Chemistry for Technician, 2nd ed., Lewis publisher, 239, 1994.

[43] P. Persson, N. Nilsson, S. Sjoberg, Structure and bonding of orthophosphate ions at the iron oxide aqueous interface, J. Colloids Interface Sci. 177 (1995) $263-275$. 
[44] Z. Mao-Xu, D. Kui-Ying, X. Shao-Hui, J. Xin, Adsorption of phosphate on hydroxyaluminum and hydroxyiron-montmorillonite complexes, J. Hazard. Mater. 165 (2009) 645-651.

[45] Y. Xiaofang, W. Dongsheng, S. Zhongxi, T. Hongxiao, Adsorption of phosphate at the aluminum hydroxide-water interface: role of the surface acid-base properties, J. Colloids Surf. A 297 (2006) 84-90.

[46] L. Lai, Q. Xie, L. Chi, W. Gu, D. Wu, Adsorption of phosphate from water by easily separable $\mathrm{Fe}_{3} \mathrm{O}_{4} @ \mathrm{SiO}_{2}$ core/shell magnetic nanoparticles functionalized with hydrous lanthanum oxide, J. Colloids Interface Sci. 465 (2016) 76-82.

[47] Y. Liang-gua, X. Yuan-yuank, Y. Hai-qin, X. Xio-dong, W. Qin, D. Bin, Adsorpion of phosphate from aqueous solution by hydroxyl-aluminum, hydroxyl-iron, hydroxyl-iron-aluminum pillard bentonites, J. Hazard. Mater. 179 (2010) 244250.

[48] S. Sairam, C.S. Meenakshi, Fluoride sorption using organic-inorganic hybrid type ion exchangers, J. Colloid Interface Sci. 333 (2009) 58-62.

[49] J. Lu, H. Liu, R. Liu, X. Zhao, L. Sun, J. Qu, Adsorptive removal of phosphate by a nanostructured $\mathrm{Fe}-\mathrm{Al}-\mathrm{Mn}$ trimetal oxide adsorbent, Powder Technol. 233 (2013) 146-154.
[50] Y. Su, W. Yang, W. Sun, O. Li, J.K. Shang, Synthesis of mesoporous ceriumzirconium binary oxide nanoadsorbents by a solvothermal process and their effective adsorption of phosphate from water, Chem. Eng. J. 268 (2015) 270 279.

[51] C. Namasivayam, K. Prathap, Recycling Fe(III)/Cr(III) hydroxide, an industrial solid waste for the removal of phosphate from water, J. Hazard. Mater. B123 (2005) 127-134.

[52] M. D’Arcy, D. Weiss, M. Bluck, R. Vilar, Adsorption kinetics: capacity and mechanism of arsenate and phosphate on a bifunctional $\mathrm{TiO}_{2}-\mathrm{Fe}_{2} \mathrm{O}_{3}$ bicomposite, J. Colloid Interface Sci. 364 (2011) 205-212.

[53] Y Yu. J.P. Chen, Key factors for optimum performance in phosphate removal from contaminated water by a Fe-Mg-La tri-metal composite sorbent, J. Colloid Interface Sci. 445 (2015) 303-311.

[54] A. Olgun, N. Atar, S. Wang, Batch and column studies of phosphate and nitrate adsorption on waste solids containing boron impurity, Chem. Eng. J. 222 (2013) 108-119. 